\title{
The Involvement of Pregnane X Receptor-regulated Pathways in the Antitumor Activity of Cisplatin
}

\author{
MEGUMI YASUDA $^{1}$, SHUICHI KISHIMOTO ${ }^{2}$, MANABU AMANO ${ }^{1}$ and SHOJI FUKUSHIMA ${ }^{2}$ \\ ${ }^{1}$ Department of Pharmacy, School of Pharmacy, Hyogo University of Health Sciences, Kobe, Japan; \\ ${ }^{2}$ Department of Pharmaceutics, Faculty of Pharmaceutical Sciences, Kobe Gakuin University, Kobe, Japan
}

\begin{abstract}
Background/Aim: Nuclear receptors regulate the expression of cellular transporters, which may be contributing factors for cisplatin $(C D D P)$ resistance. This study aimed to clarify whether nuclear receptor ligands could be potentially used as drugs to overcome CDDP resistance. Materials and Methods: Caspase-3 activity was measured using a fluorogenic substrate. mRNA levels were determined using real-time polymerase chain reaction. Results: Pregnane $X$ receptor (PXR) showed an expression level change dependent on caspase-3 activation by CDDP in HepG2. Rifampicin, a PXR agonist, reduced the accumulation of CDDP and suppressed growth inhibition and caspase-3 activation in HepG2 after CDDP exposure. Leflunomide, a PXR antagonist, significantly enhanced caspase-3 activation by CDDP in HepG2 and CDDPresistant HepG2/R. Conclusion: These results suggest that $P X R$ can modify the antitumor activity of $C D D P$, presumably through regulating the expression of transporters, which control intracellular CDDP concentration. Thus, PXR antagonists can be further investigated as potential drugs capable of overcoming CDDP resistance.
\end{abstract}

Cisplatin (CDDP) is an anticancer drug that has been used to treat many types of solid tumors. Treatment with CDDP has been shown to ultimately induce apoptosis after its uptake into cells; thus, CDDP exhibits an antitumor effect. It has been thought that CDDP can easily penetrate the membrane of cancer cells because it is a neutral metal complex; however, the involvement of both active transport and passive transport in the intracellular uptake of CDDP has been reported in many cell lines $(1,2)$. For example, the

Correspondence to: Shuichi Kishimoto, Department of Pharmaceutics, Faculty of Pharmaceutical Sciences, Kobe Gakuin University, Minatojima 1-1-3, Chuo-ku, Kobe 650-8586, Japan. Tel: +81 789744753, Fax: +81 789744753, e-mail: skisimot@ pharm. kobegakuin.ac.jp

Key Words: Cisplatin, pregnane $\mathrm{X}$ receptor, transporter, apoptosis. increase in the expression levels of drug efflux transporter multidrug resistance-associated protein 2 (MRP2) has been reported to cause CDDP resistance in human hepatic adenocarcinoma SK-HEP-1 and human melanoma MeWo cell lines $(3,4)$. In addition, overexpression of multidrug resistance-associated protein 3 (MRP3) in human the glioma NHG2 cell line has been reported to reduce sensitivity to CDDP. These transporters are known to be involved in extracellular export of CDDP (5). Moreover, in CDDPresistant cells, the decrease in intracellular platinum amount correlates with reduced expression or activity levels of solute carrier family 31 member 1 (SLC31A1), which transports copper into cells $(6,7)$, organic cation transporters (OCT) 1 , 2 and $3(8,9)$ and $\mathrm{Na}^{+}, \mathrm{K}^{+}$-ATPase $(10,11)$. All of these proteins might presumably transport CDDP into the cells. Various transporters related to the intracellular accumulation of CDDP have been reported depending on the cell type; however, specific transporters responsible for the acquired resistance to CDDP have not been clarified. In our previous study, we reported that CDDP-resistant tumors with low intracellular platinum content consist of heterogeneous cell populations with expression level changes of several transporters. Thus, to overcome CDDP resistance, it might be necessary to focus on regulatory proteins rather than the transporters themselves (12).

Nuclear receptors, as ligand-dependent transcription regulators, can negatively or positively control the expression of their target genes. In addition, these receptors are known to strictly control important biological phenomena such as cell differentiation, development, metabolism and homeostasis (13). Pregnane $\mathrm{X}$ receptor (PXR) and constitutive androstane receptor (CAR) mainly regulate the expression of cytochromes P450 (CYPs), conjugating enzymes and transporters involved in drug metabolism and excretion from the body. Activated peroxisome proliferatoractivated receptors (PPARs) are necessary in a variety of physiological processes, including lipid and glucose homeostasis, inflammation, and organ protection. In recent years, it has been reported that some anticancer agents affect the expression of nuclear receptors, which play essential 
roles in cancer biology, thus directly influencing the efficacy of treatment. Induction of PXR expression in human breast cancer cells was reported to affect their responsiveness to some anticancer drugs, such as taxanes, doxorubicin, tamoxifen, and vinblastine (14). In leukemia cells CAR induction significantly altered the expression of certain enzymes (i.e., CYP2B6, CYP3A4) and transporters (i.e., multiple drug resistance 1 (MDR1)) (15). These changes improved metabolic profiles and antineoplastic properties of cyclophosphamide-containing regimens. The roles of PPARs in colorectal cancer progression have been extensively investigated. PPARs can function as tumor suppressors or promoters, suggesting that these receptors are potential drug targets for cancer prevention and treatment (16).

In addition, the aforementioned nuclear receptors may influence the cytotoxicity of CDDP. PXR and CAR control the expression of transporters that transport CDDP out of cells $(14,17)$. Drugs that act on PPARs have been widely reported to suppress CDDP-induced nephrotoxicity (18) and ototoxicity (19) and enhance its antitumor activity (20). Therefore, it is expected that combined use of nuclear receptor ligands with CDDP may enhance the effect of CDDP or overcome tumor resistance to the drug. Therefore, in this study, we examined the relationship between the effect of CDDP on the expression levels of nuclear receptors PXR, CAR PPAR $\alpha$, and PPAR $\gamma$ as well as the antitumor activity of CDDP in the presence of different nuclear receptor ligands.

\section{Materials and Methods}

Cell culture. Human hepatocellular carcinoma HepG2 cells were purchased from Dainippon Pharmaceutical (Osaka, Japan). Cells were maintained in minimum essential medium (Nacalai Tesque, Kyoto, Japan) containing $10 \%$ fetal bovine serum at $37^{\circ} \mathrm{C}$ in humidified air with $5 \% \mathrm{CO}_{2}$. CDDP-resistant HepG2 cells were previously isolated via a three-step CDDP exposure, using 1, 3, and $5 \mu \mathrm{M}$ of CDDP, respectively (12). The established cell line was named HepG2/R.

Cytotoxicity assay. Cytotoxicity studies were carried out using sulforhodamine B (SRB, Nacalai Tesque) microculture colorimetric assay. The assay was also used to determine cell density by measuring cellular protein content. Briefly, HepG2 cells were plated into 96-well plates at a density of $4.0 \times 10^{3}$ cells per well on day 0 and exposed to rifampicin (RFP, Nacalai Tesque) on day 1 and/or CDDP on day 2. The SRB assay was carried out after $72 \mathrm{~h}$ of plating, $48 \mathrm{~h}$ or $24 \mathrm{~h}$ in the presence of RFP or CDDP, respectively. Following incubation with the drugs, the cells were fixed with $10 \%$ trichloroacetic acid in situ, washed with water, and dried. Thereafter, $0.4 \%$ SRB solution in $1 \%$ acetic acid was added, and the cells were incubated at room temperature for $30 \mathrm{~min}$. The cells were washed again, the bound stain was solubilized with trisma base solution (Nacalai Tesque), and the absorbance was measured at $570 \mathrm{~nm}$ in a microplate reader (Model 550, BIO-RAD, Tokyo, Japan). The data were evaluated by using Microsoft Excel, and the relative surviving cell fractions were calculated in each experimental group with respect to the control group. All data represent the average value from 5 wells.

Caspase-3 assay. Caspase-3 enzyme activity was measured by proteolytic cleavage of the fluorogenic substrate N-Acetyl-Asp-GluVal-Asp-7-amido-4-trifluoromethylcoumarin (Ac-DEVD-AFC) using Caspase-3 Fluorometric Assay Kit (BioVision, Milpitas, CA, USA). HepG2 and HepG2/R cells were plated at a density of $2.0 \times 10^{5}$ cells per well into 6 -well plates on day 0 and exposed to $100 \mu \mathrm{M}$ RFP or $100 \mu \mathrm{M}$ leflunomide (LEF, Nacalai Tesque, Kyoto, Japan) on day 1 and/or 4 or $25 \mu \mathrm{M} \mathrm{CDDP}$ on day 2 . After $72 \mathrm{~h}$ of plating ( $48 \mathrm{~h}$ or $24 \mathrm{~h}$ in the presence of LEF or CDDP, respectively), the cells were harvested and washed with cold phosphate-buffered saline (PBS). The pellets were lysed using $100 \mu \mathrm{l}$ of cell lysis buffer, and then placed on ice. A small portion (5\%) of the cell lysate was used to determine the protein content using a BCA Protein Assay Kit (Pierce, IL, USA). The cell lysates were adjusted to a protein concentration of $0.25 \mu \mathrm{g} / \mu \mathrm{l}$ with cell lysis buffer. The reaction mixtures were prepared in a 96-well plate and contained the following components: $50 \mu \mathrm{l}$ of the sample, $50 \mu \mathrm{l}$ of $2 \mathrm{X}$ reaction buffer containing $10 \mathrm{mM}$ DTT, and $5 \mu \mathrm{l}$ of $2 \mathrm{mM}$ Ac-DEVD-AFC solution. The reaction mixtures were incubated at $37^{\circ} \mathrm{C}$ for $1 \mathrm{~h}$ and at room temperature for another hour. The fluorescence was measured on a fluorescence reader (Versa Fluor fluorometer, BioRad Laboratories, CA, USA). They were expressed as a relative value with respect to the control group.

Intracellular platinum accumulation. HepG2 cells were seeded into $75-\mathrm{cm}^{2}$ tissue culture flasks with a cell density of $1.0 \times 10^{6}$ per flask at $0 \mathrm{~h}$ and exposed to $100 \mu \mathrm{M}$ RFP at $24 \mathrm{~h}$ and/or $25 \mu \mathrm{M}$ CDDP at $48 \mathrm{~h}$. Immediately after a $24 \mathrm{~h}$ exposure to CDDP, the cells were harvested and washed three times with cold PBS. A small portion (5\%) of the cells from each experimental group was used to determine the protein content using a BCA Protein Assay Kit (Pierce, Rockford, IL, USA). The remaining cell pellets were suspended in $1.5 \mathrm{ml}$ of a mixture of perchloric acid and $30 \%$ hydrogen peroxide at the ratio of $1: 2$ and digested for $12 \mathrm{~h}$ at $65^{\circ} \mathrm{C}$. The amount of platinum in the samples was determined using an SPS 3100 Inductively Coupled Plasma Optical Emission Spectrometer (ICPOES, Hitachi High-Tech Science Corporation, Tokyo, Japan). The results were expressed as ng of platinum per mg of protein.

RNA extraction and real-time polymerase chain reaction (RT-PCR). Total RNA was extracted using Sepasol-RNA I Super (Nacalai Tesque, Kyoto, Japan) in accordance with the manufacturer's protocol. The quality and concentration of RNA in each sample was confirmed by spectrophotometry using NanoDrop Lite (Thermo Fisher Scientific, Yokohama, Japan). cDNA was produced from total RNA by reverse transcription using a PrimeScript II First Strand cDNA Synthesis Kit (Takara Bio, Shiga, Japan). Amplification was performed using RotorGene Q (Qiagen, Tokyo, Japan) with a Rotor-Gene SYBR Green PCR Kit (Qiagen). Glyceraldehyde 3-phosphate dehydrogenase (GAPDH) was used for normalization of the relative expression levels. The primers for RT-PCR, synthesized by BEX (Tokyo, Japan), were designed as follows: PXR, forward 5'-TGAGGAGGAGTATGTGC TCATG-3', reverse 5'-GCAGTGTCCATCTGTCTTGG-3'; CAR, forward 5'-TGAGCTGAGGAACTGTGTGG-3', reverse 5'-TGAT GTCTGCGAAGTGTGTG-3'; PPAR $\alpha$, forward 5'-ATTCGCCATGC TGTCTTCTG-3', reverse 5'-CATCCGACTCCGTCTTCTTG-3'; 
(a) $4 \mu \mathrm{M}$

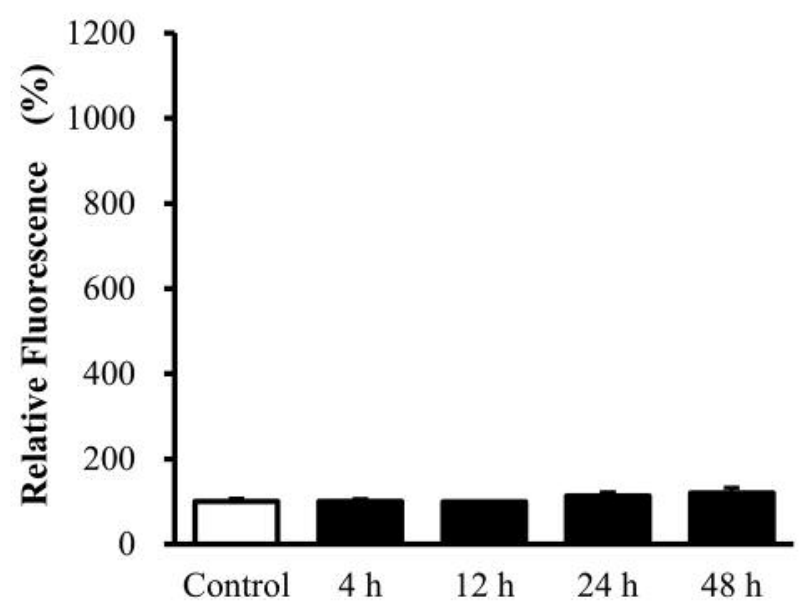

(b) $25 \mu \mathrm{M}$

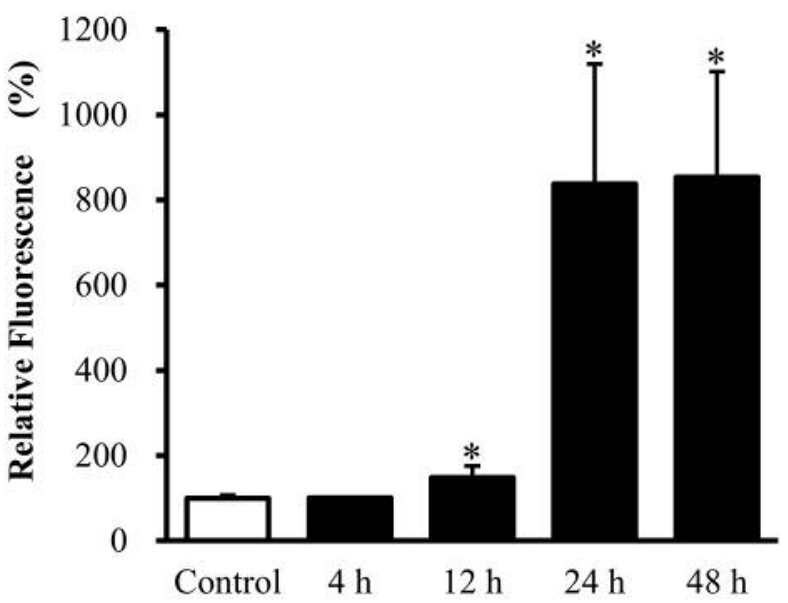

Figure 1. Caspase-3 activation induced by CDDP in HepG2. The graphs represent caspase-3 activity values in HepG2 cells exposed to 4 (a) or $25 \mu \mathrm{M}(\mathrm{b})$ of CDDP for 4 to $48 \mathrm{~h}$. Caspase-3 activity was assessed by using Caspase-3 Fluorometric Assay Kit. The relative fluorescence is expressed as the fold increase with respect to the control group. Data are presented as means \pm SD for 3 individual experiments. *p<0.05 vs. control.

PPAR $\gamma$, forward 5'-GCAGGAGATCACAGAGTATGC-3', reverse 5' GGCTTGTAGCAGGTTGTCTTG-3'; GAPDH, forward 5'-AACGG GAAGCTTGTCATCAATGGAAA-3'; reverse 5'-GCATCAGCAG AGGGGGCAGAG- 3 '. The PCR conditions were set as follows: $95^{\circ} \mathrm{C}$ for $5 \mathrm{sec}$ and $60^{\circ} \mathrm{C}$ for $10 \mathrm{sec}, 40$ cycles. The cycle threshold (CT) indicated the fractional cycle number at which the PCR product was first detected above a fixed threshold. Relative mRNA levels were determined using the $2^{-\Delta \Delta C T}$ method.

Statistical analysis. Results are expressed as means \pm standard deviation (SD). Statistical analysis was performed with Microsoft Excel using Dunnett's test for multiple comparisons with a control group. $p<0.05$ was considered significant.

\section{Results}

Caspase-3 activation induced by CDDP. Caspase-3 activity was examined over a 48-h time period in HepG2 exposed to 4 or $25 \mu \mathrm{M}$ of CDDP (Figure 1). The concentrations of 4 and $25 \mu \mathrm{M}$ of CDDP were selected as they are the $\mathrm{IC}_{50}$ and $\mathrm{IC}_{90}$ values, respectively. Treatment with $4 \mu \mathrm{M}$ of CDDP had no effect on caspase- 3 activity even after $48 \mathrm{~h}$. In cells exposed to $25 \mu \mathrm{M}$ of CDDP, caspase-3 activity increased 8.6- and 10times after treatment for 24 or $48 \mathrm{~h}$, respectively, compared to the control. The results of the experiment showed that in HepG2 cell line, exposure to $4 \mu \mathrm{M}$ of CDDP resulted in growth suppression, but it did not lead to apoptosis. It was also observed that treatment with $25 \mu \mathrm{M}$ of CDDP for $24 \mathrm{~h}$ or more is required to induce apoptosis.

Changes in the expression levels of nuclear receptors induced by CDDP exposure. mRNA levels of nuclear receptors PXR, CAR, PPAR $\alpha$, and PPAR $\gamma$ were measured in HepG2 cell line after CDDP exposure (Figures 2 and 3). In the cells treated with $4 \mu \mathrm{M}$ of CDDP, the expression of PXR was slightly increased throughout the experiment, whereas the levels of CAR, PPAR $\alpha$, and PPAR $\gamma$ showed a decreasing tendency, reaching the lowest values after $12 \mathrm{~h}$ of treatment. In the cells treated with $25 \mu \mathrm{M}$ of CDDP, the levels of PXR temporarily decreased, reaching a minimum value after $12 \mathrm{~h}$ of exposure. The expression of PPAR $\alpha$ was greatly reduced, reaching the minimum value after $12 \mathrm{~h}$ of exposure and remained low for the rest of the experiment. On the other hand, the expression of CAR and PPAR $\gamma$ showed biphasic changes. Thus, PXR and PPAR $\alpha$ expression levels correlated with exposure to CDDP, whereas no correlation between the expression levels of CAR and $\operatorname{PPAR} \gamma$ and exposure to CDDP could be observed.

Effects of PXR agonist RFP on CDDP antitumor activity. The effect of RFP, a PXR agonist, on the CDDP cytotoxicity against HepG2 was evaluated (Figure 4). HepG2 proliferation was not affected by $100 \mu \mathrm{M}$ of RFP. $\mathrm{IC}_{50}$ value of CDDP alone was $2.3 \pm 0.5 \mu \mathrm{M}$; however, this value increased to $8.5 \pm 1.5 \mu \mathrm{M}$ when CDDP was used in combination with RFP. Thus, it was found that RFP was able to significantly inhibit the cytotoxic effects of CDDP. Similarly, RFP significantly suppressed caspase-3 activation in cells exposed to $25 \mu \mathrm{M}$ of CDDP (Figure 5). Furthermore, the effect of RFP on the intracellular accumulation of CDDP was examined. The intracellular platinum content after $24 \mathrm{~h}$ treatment with $25 \mu \mathrm{M}$ of CDDP was $266.4 \pm 92.3 \mathrm{ng} / \mathrm{mg}$ 
(a) PXR

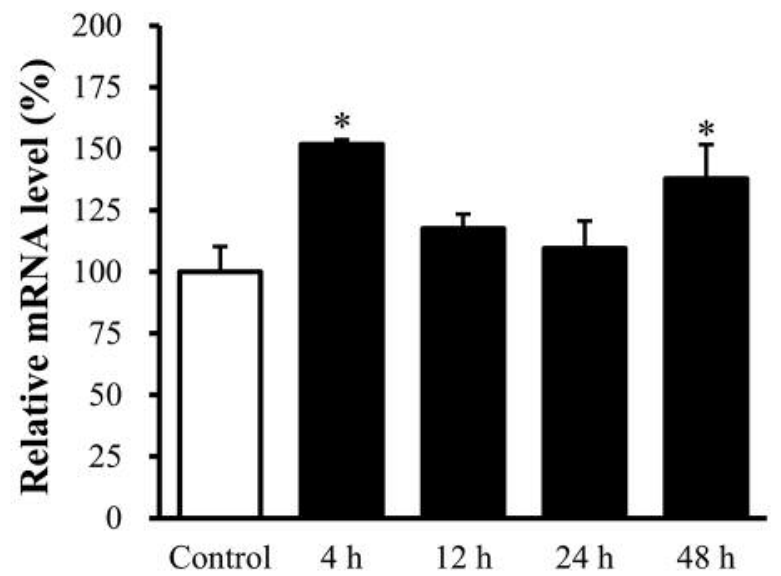

(c) PPAR $\alpha$

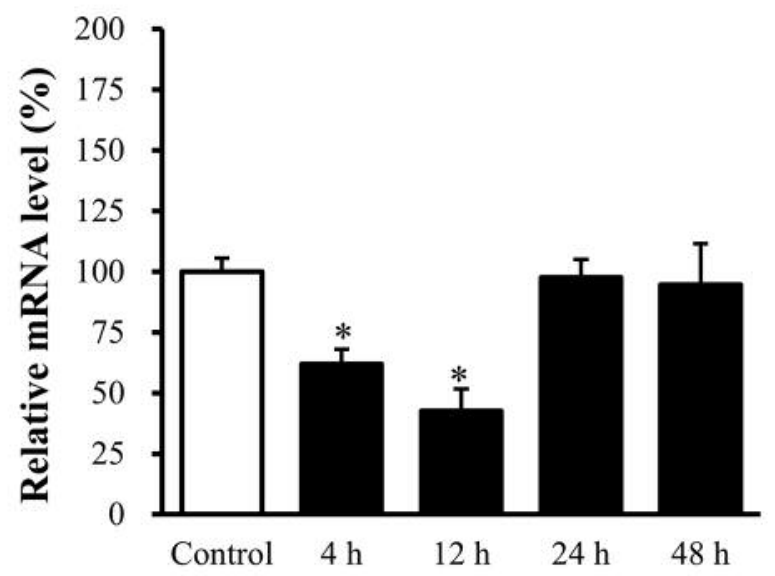

(b) CAR

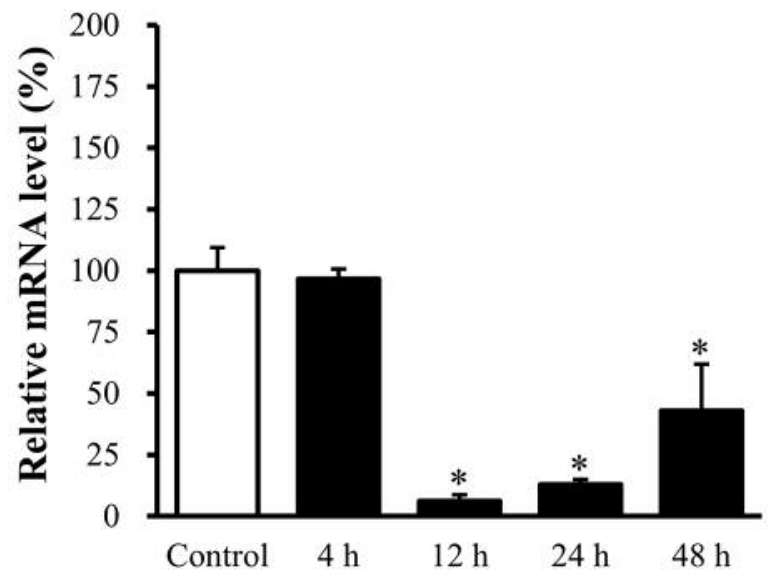

(d) PPAR $\gamma$

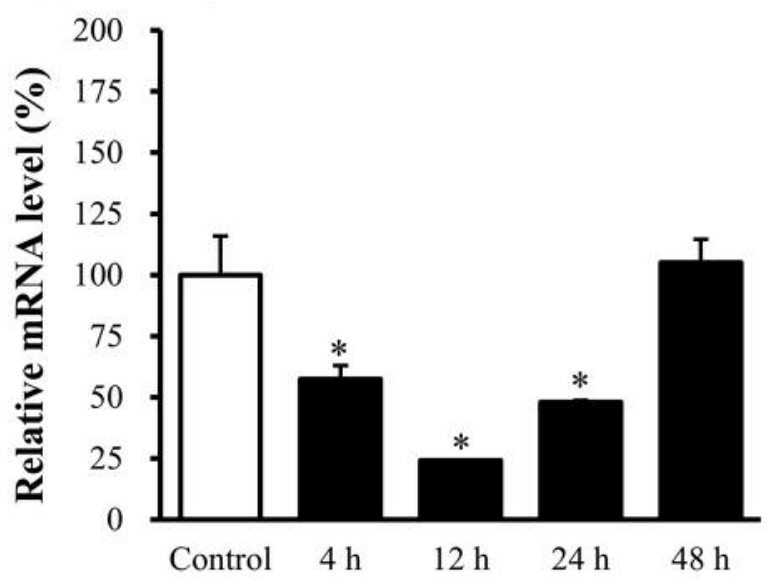

Figure 2. Relative mRNA levels of nuclear receptors in HepG2 exposed to $4 \mu M$ of CDDP for 4 to 48 h. mRNA levels of PXR (a), CAR (b), PPAR $\alpha$ $(c)$, and PPAR $\gamma(d)$ were normalized to GAPDH mRNA expression level. The relative mRNA levels of each nuclear receptor are expressed as the fold increase with respect to the control group. Data are presented as means $\pm S D$ for 3 individual experiments. ${ }^{*} p<0.05 v s$. control.

protein; however, when CDDP was used in combination with RFP, this value decreased to $142.7 \pm 53.8 \mathrm{ng} / \mathrm{mg}$ protein. It was suggested that suppression of caspase- 3 activation and the reduced cytotoxic effect of CDDP when used in combination with RFP was correlated to the decreased amount of intracellular platinum.

Effects of PXR antagonist LEF on CDDP resistance. We have demonstrated that the HepG2/R cell line developed in our laboratory is 2.6 times more resistant to CDDP and the intracellular platinum amount in such cells is reduced by $30 \%$ compared to the parent HepG2 cell line. Also, in the HepG2/R cell line, PXR expression levels were increased about 1.5 times compared to HepG2. LEF, which is an antirheumatic drug, was selected as a PXR antagonist.
Caspase-3 activity was evaluated in both HepG2 and HepG2/R cell lines after exposure to CDDP, LEF and the combination of both drugs (Figure 6). The results showed that LEF alone did not affect caspase-3 activity. In HepG2 cell line, exposure to $25 \mu \mathrm{M}$ of CDDP increased caspase- 3 activity 8 times compared to control, while CDDP used in combination with LEF resulted in 12-times higher caspase3 activity compared to the control group. In HepG2/R, exposure to $25 \mu \mathrm{M}$ of CDDP increased caspase- 3 activity 2 times, while CDDP used in combination with LEF was able to increase caspase- 3 activity 6 times compared with the control group. Thus, the results of the experiment clearly demonstrated, that PXR antagonist LEF was able to enhance CDDP-induced cytotoxicity in HepG2/R cells with high PXR expression. 
(a) PXR

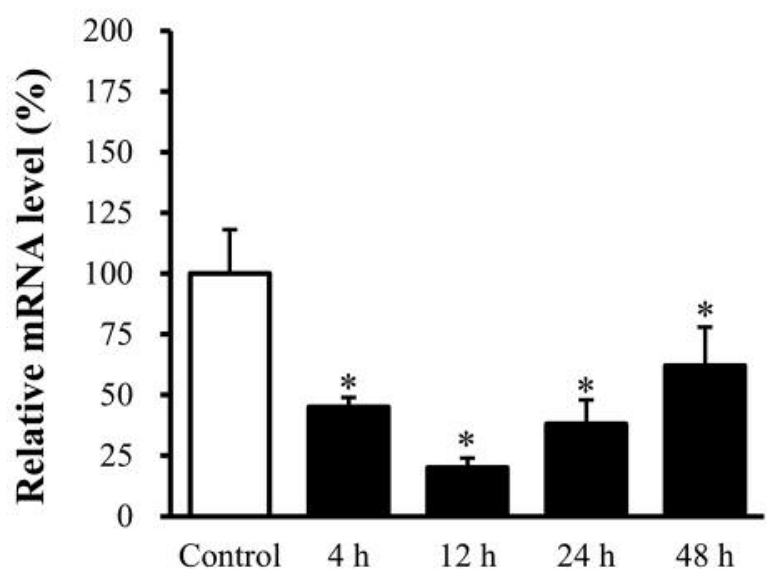

(c) PPAR $\alpha$

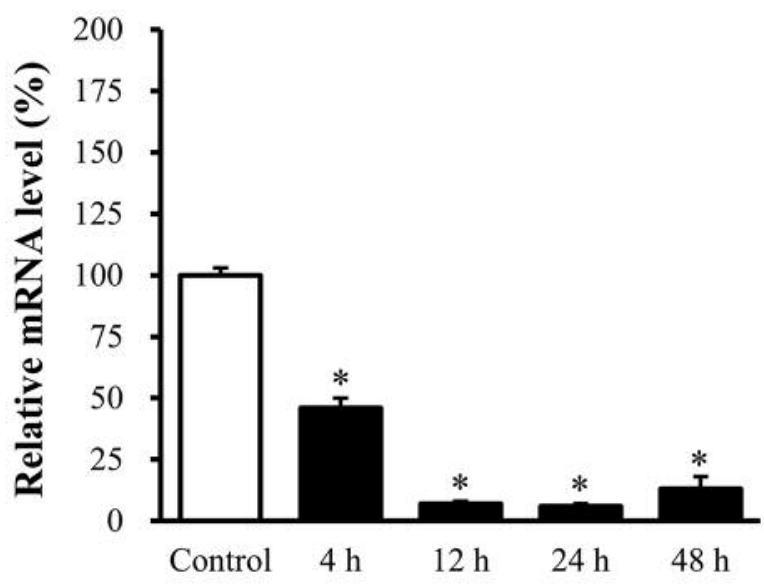

(b) CAR

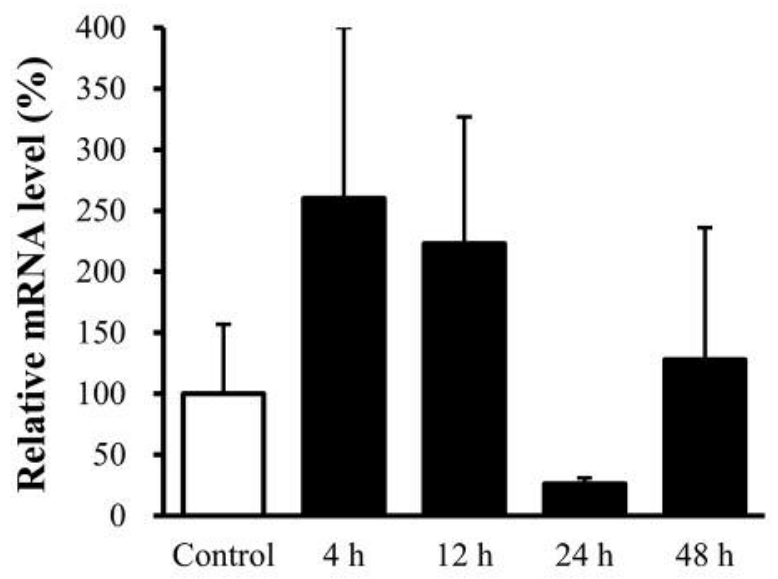

(d) PPAR $\gamma$

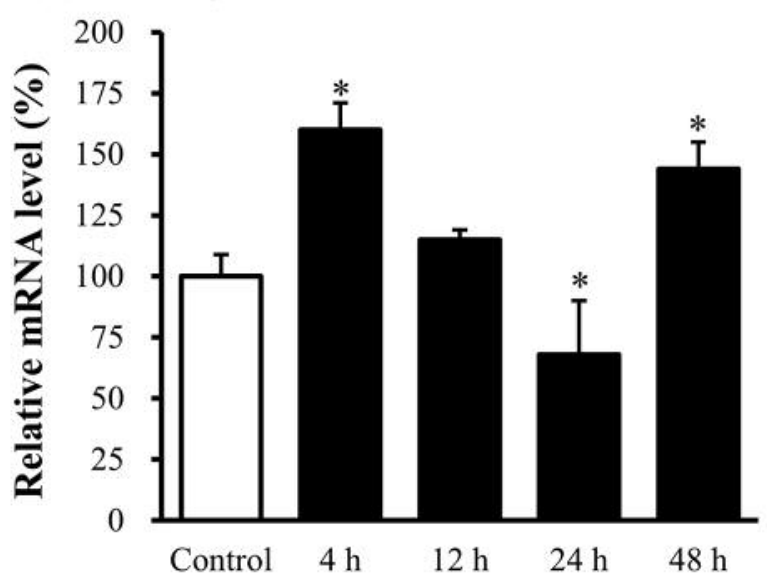

Figure 3. Relative mRNA levels of nuclear receptors in HepG2 exposed to $25 \mu M$ of CDDP for 4 to 48 h. mRNA levels of PXR (a), CAR (b), PPAR $(c)$, and PPAR $\gamma(d)$ were normalized to GAPDH mRNA expression level. The relative mRNA levels of each nuclear receptor are expressed as the fold increase with respect to the control group. Data are presented as means $\pm S D$ for 3 individual experiments. $* p<0.05 v s$. control.

\section{Discussion}

CDDP is an anticancer drug used for the treatment of many solid tumors; however, development of resistance to the drug is a major problem in the clinic. Low intracellular platinum levels observed in many CDDP-resistant cells are associated with decreased intracellular uptake, enhanced extracellular export, or alterations in both pathways $(1,2)$. Various transporters play critical roles in these pathways and changes in expression levels of these transporters can result in acquiring resistance to CDDP. Nuclear receptors are known to be involved in expression regulation of transporters (21, 22); however, their role in CDDP antitumor activity has remained unclear.

In this study, HepG2 cell line, which was expected to express nuclear receptors for controlling the expression of transporters and metabolic enzymes, was used. Two cells were exposed to two different CDDP concentrations: low CDDP concentration was able to inhibit cell culture growth, whereas higher concentration resulted in both growth inhibition and caspase- 3 activation. The expression levels of nuclear receptors CAR and PPAR $\gamma$ were not affected by CDDP exposure whereas expression of nuclear receptor PPAR $\alpha$ decreased as CDDP concentration increased. On the other hand, expression levels of nuclear receptor PXR tended to slightly increase at a low concentration of CDDP, while high CDDP concentration caused significantly decreased expression. Therefore, it was suggested that PXR is a nuclear receptor that is responsible for protecting cells, because its expression level was increased as a result of CDDP exposure. It was also observed, that reduced PXR expression may result in cell apoptosis. Thus, PXR plays 


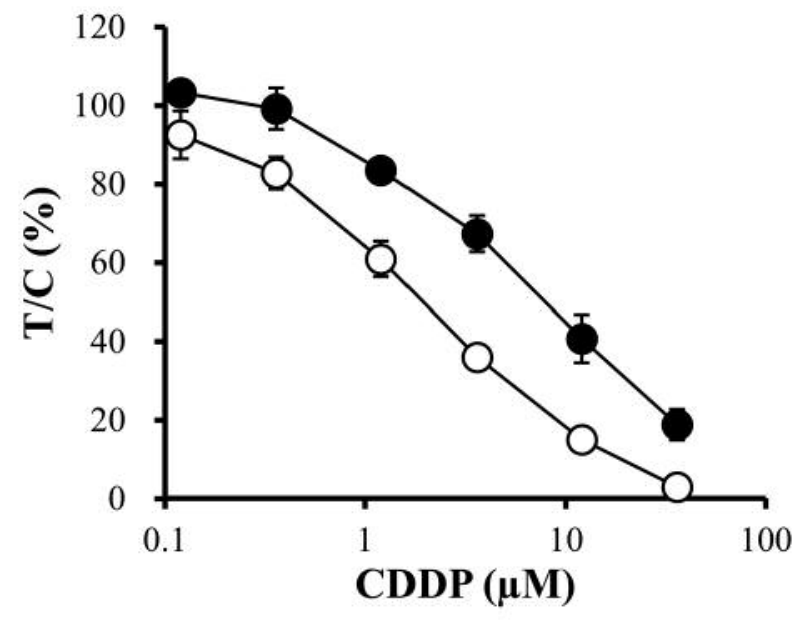

Figure 4. Effect of RFP on the cytotoxicity of CDDP in HepG2. The graphs represent proliferation rates in HepG2 cells treated with CDDP and CDDP combined with RFP. Cells were exposed to $100 \mu M$ of RFP for $48 \mathrm{~h}$ and/or CDDP for $24 \mathrm{~h}$. Cytotoxicity was assessed by the sulforhodamine B assay. Opened circles: CDDP; closed circles: $C D D P$ combined with RFP. Data are presented as means $\pm S D$ for 3 individual experiments.

\section{(a) HepG2}

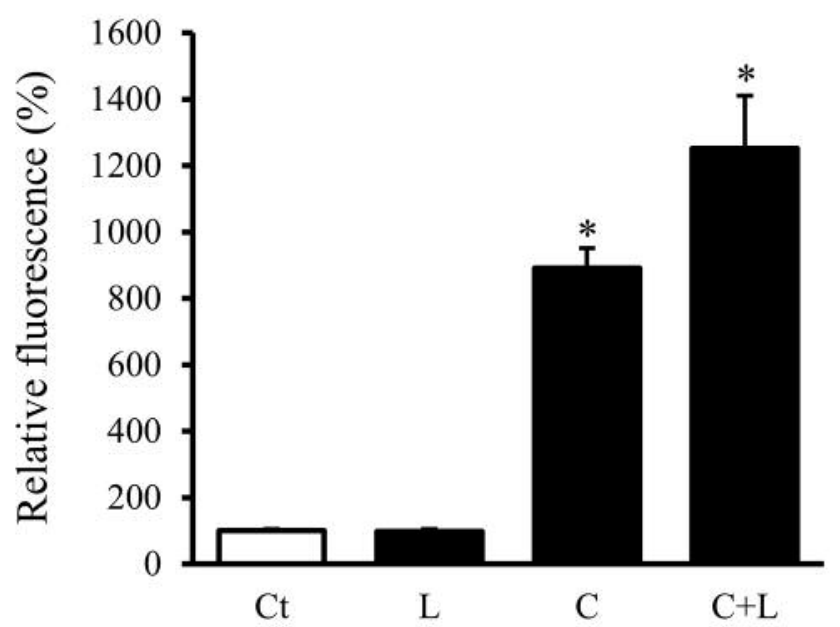

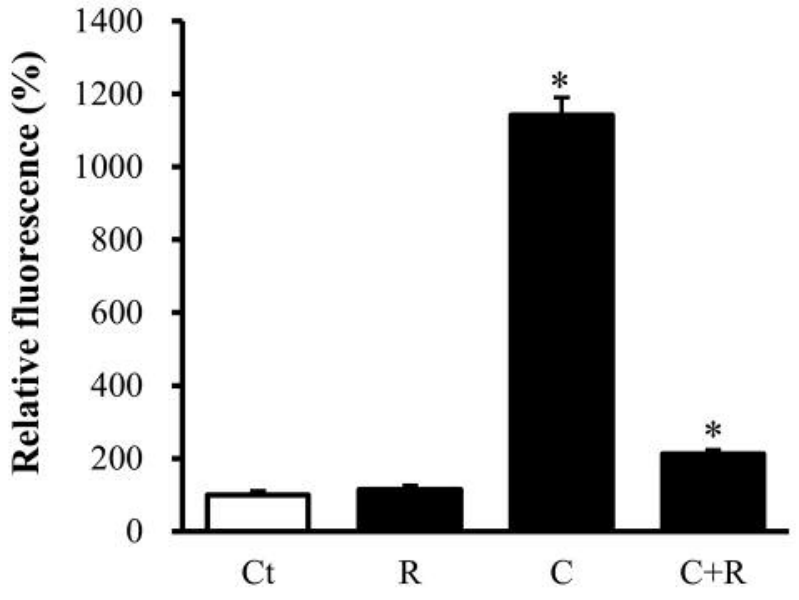

Figure 5. Effect of RFP on caspase-3 activation induced by CDDP in HepG2. Cells were exposed to $100 \mu \mathrm{M}$ of RFP for $48 \mathrm{~h}$ and/or $25 \mu \mathrm{M}$ of CDDP for 24 h. Caspase-3 activity was assessed by Caspase-3 Fluorometric Assay Kit. The graph represents caspase-3 activity in HepG2 cells exposed to CDDP, RFP or both. The relative fluorescence in each group is expressed as the fold increase with respect to the control group. Ct: Control, R: RFP, C: CDDP, C+R: CDDP and RFP. Data are presented as means $\pm S D$ for 3 individual experiments. ${ }^{*} p<0.05 \mathrm{vs}$. control.

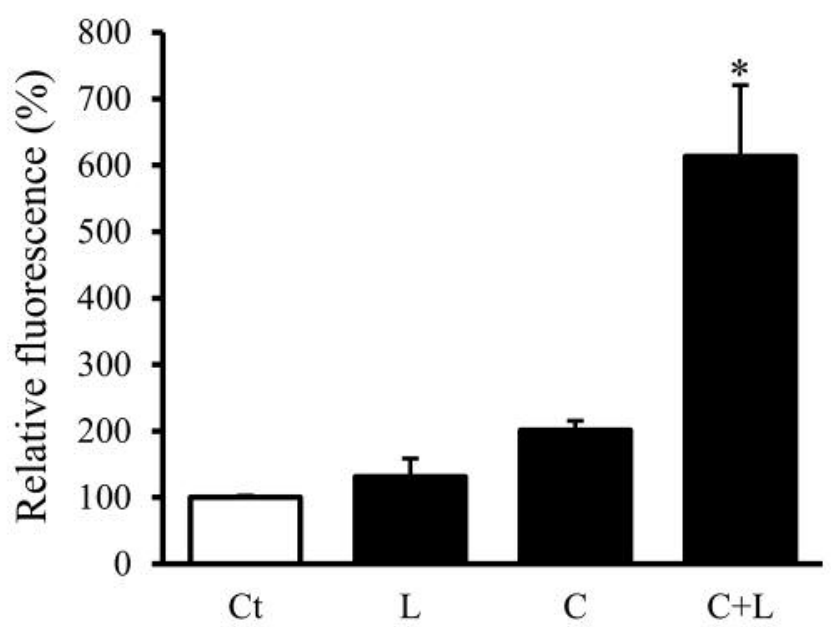

Figure 6. Effect of LEF on caspase-3 activation induced by CDDP in HepG2 (a) and HepG2/R (b). Cells were exposed to $100 \mu M$ of LEF for $48 \mathrm{~h}$ and/or $25 \mu \mathrm{M}$ of CDDP for $24 \mathrm{~h}$. Caspase-3 activity was assessed by Caspase-3 Fluorometric Assay Kit. The relative fluorescence in each group in both HepG2 and HepG2/R cell lines is expressed as the fold increase with respect to the control group. Ct: Control, L: LEF, C: CDDP, C+L: $C D D P$ and $L E F$. Data are presented as the means $\pm S D$ for 3 individual experiments. ${ }^{*} p<0.05 \mathrm{vs}$. control.

an important role in protecting cells from toxic xenobiotics. In fact, PXR has been reported to alter therapeutic response to anticancer drugs by regulating the expression of drugmetabolizing enzymes and drug transporters (23). Harmsen et al. demonstrated that several widely used anticancer drugs activate PXR-mediated induction of P-glycoprotein (P-gp) and consequently decrease the intracellular accumulation of $\mathrm{P}$-gp substrates in the colon 
adenocarcinoma-derived LS180 cell line (24). In addition, the cytotoxic activity of doxorubicin has been shown to be reduced when cells are pretreated with a PXR agonist RFP. To investigate the role of PXR in the cytotoxicity of CDDP, the effects of RFP pretreatment were examined. In HepG2, RFP inhibited the cytotoxic effect and caspase- 3 activation induced by CDDP, and also reduced intracellular platinum accumulation. Activation of PXR is known to increase MRP2 expression, which is a drug efflux transporter involved in the efflux of CDDP. Therefore, it was suggested that in cells pretreated with RFP, increased MRP2 expression reduced intracellular CDDP accumulation, thereby reducing CDDP activity.

One of the underlying mechanisms for resistance to CDDP is a decrease in the intracellular accumulation of CDDP due to high MRP2 expression. MRP2 expression is regulated by PXR and CDDP-resistant cells may show an increase in either expression or activity of PXR. All three CDDP resistant cell lines established in our laboratory had increased PXR expression levels (data not shown). PXR is known to induce CYP3A4 and MDR1 expression in multiple cell types along with some enzymes and transporters that are known to detoxify microtubule-binding and topoisomerase-binding drugs $(25,26)$. Several reports suggested that PXR antagonists could prevent or overcome drug resistance in certain tumor types $(27,28)$. Ekins et al. studied novel small molecule PXR antagonists using computational pharmacophore and docking tools and reported that LEF might be a promising drug (29). In HepG2, pretreatment with LEF resulted in approximately $40 \%$ increase in caspase- 3 activation compared to CDDP alone. Furthermore, in HepG2/R, pretreatment with LEF induced approximately 3fold increase in caspase-3 activation over CDDP alone, which did not show significant effects. Thus, PXR antagonist used in combination with CDDP sensitized cancer cells and restored sensitivity in CDDP-resistant cells with increased PXR expression.

In conclusion, we have previously described that CDDP resistance is caused by complicated expression changes of various transporters. In this study, we focused on nuclear receptors involved in the regulation of expression of these transporters and metabolic enzymes. In response to CDDP exposure, PXR expression levels were altered dependent on caspase-3 activation. PXR agonist RFP suppressed the cytotoxicity of CDDP, suggesting that PXR up-regulation is induced as a protective response in cells exposed to CDDP. As treatment with LEF, which is a PXR antagonist, resulted in the ability to overcome CDDP resistance, incorporation of a nuclear receptor ligand into cancer treatment strategies can be suggested. Further studies will be required on optimal PXR antagonist selection, combination schedule, and in vivo combination in order to fully overcome CDDP resistance.

\section{Conflicts of Interest}

The Authors report no conflicts of interest regarding this study.

\section{Authors' Contributions}

MY and SK conceived and designed the experiments; MY performed the experimental work; all Authors participated in data analysis; MY wrote the manuscript; SK reviewed and revised the manuscript. All Authors have read and approved the final manuscript.

\section{Acknowledgements}

The Authors would like to thank Editage (www.editage.jp) for English language editing.

\section{References}

1 Siddik ZH: Cisplatin: mode of cytotoxic action and molecular basis of resistance. Oncogene 22(47): 7265-7279, 2003. PMID: 14576837. DOI: 10.1038/sj.onc.1206933

2 Hall MD, Okabe M, Shen DW, Liang XJ and Gottesman MM: The role of cellular accumulation in determining sensitivity to platinum-based chemotherapy. Annu Rev Pharmacol Toxicol 48: 495-535, 2008. PMID: 17937596. DOI: 10.1146/annurev. pharmtox.48.080907.180426

3 Zhou Y and Ling XL: Establishment of a cisplatin-induced multidrug resistance cell line SK-Hep1/DDP. Chin J Cancer 29(2): 167-171, 2010. PMID: 20109345.

4 Liedert B, Materna V, Schadendorf D, Thomale J and Lage H: Overexpression of cMOAT (MRP2/ABCC2) is associated with decreased formation of platinum-DNA adducts and decreased G2-arrest in melanoma cells resistant to cisplatin. J Invest Dermatol 121(1): 172-176, 2003. PMID: 12839578. DOI: 10.1046/j.1523-1747.2003.12313.x

5 Haga S, Hinoshita E, Ikezaki K, Fukui M, Scheffer GL, Uchiumi $\mathrm{T}$ and Kuwano $\mathrm{M}$ : Involvement of the multidrug resistance protein 3 in drug sensitivity and its expression in human glioma. Jpn J Cancer Res 92(2): 211-219, 2001. PMID: 11223551. DOI: 10.1111/j.1349-7006.2001.tb01084.x

6 Song IS, Savaraj N, Siddik ZH, Liu P, Wei Y, Wu CJ and Kuo MT: Role of human copper transporter Ctr1 in the transport of platinum-based antitumor agents in cisplatin-sensitive and cisplatin-resistant cells. Mol Cancer Ther 3(12): 1543-1549, 2004. PMID: 15634647.

7 Zisowsky J, Koegel S, Leyers S, Devarakonda K, Kassack MU, Osmak $\mathrm{M}$ and Jaehde $\mathrm{U}$ : Relevance of drug uptake and efflux for cisplatin sensitivity of tumor cells. Biochem Pharmacol 73(2): 298307, 2007. PMID: 17097621. DOI: 10.1016/ j.bcp.2006.10.003

8 Yonezawa A, Masuda S, Yokoo S, Katsura T and Inui K: Cisplatin and oxaliplatin, but not carboplatin and nedaplatin, are substrates for human organic cation transporters (SLC22A1-3 and multidrug and toxin extrusion family). J Pharmacol Exp Ther 319(2): 879886, 2006. PMID: 16914559 . DOI: $10.1124 /$ jpet.106.110346

9 Zhang S, Lovejoy KS, Shima JE, Lagpacan LL, Shu Y, Lapuk A, Chen Y, Komori T, Gray JW, Chen X, Lippard SJ and Giacomini KM: Organic cation transporters are determinants of oxaliplatin cytotoxicity. Cancer Res 66(17): 8847-8857, 2006. PMID: 16951202. DOI: 10.1158/0008-5472.CAN-06-0769 
10 Kishimoto S, Kawazoe Y, Ikeno M, Saitoh M, Nakano Y, Nishi Y, Fukushima $\mathrm{S}$ and Takeuchi Y: Role of $\mathrm{Na}^{+}, \mathrm{K}^{+}$-ATPase alpha1 subunit in the intracellular accumulation of cisplatin. Cancer Chemother Pharmacol 57(1): 84-90, 2006. PMID: 16044341. DOI: $10.1007 / \mathrm{s} 00280-005-0003-x$

11 Andrews PA, Mann SC, Huynh HH and Albright KD: Role of the $\mathrm{Na}^{+}, \mathrm{K}^{+}$-adenosine triphosphatase in the accumulation of cisdiamminedichloroplatinum(II) in human ovarian carcinoma cells. Cancer Res 51(14): 3677-3681, 1991. PMID: 1648442.

12 Kishimoto $S$, Yasuda $M$ and Fukushima $S$ : Changes in the expression of various transporters as influencing factors of resistance to cisplatin. Anticancer Res 37(10): 5477-5484, 2017. PMID: 28982859. DOI: 10.21873/anticanres.11977

13 Hakkola J, Bernasconi C, Coecke S, Richert L, Andersson TB and Pelkonen O: Cytochrome P450 induction and xeno-sensing receptors pregnane $\mathrm{X}$ receptor, constitutive androstane receptor, aryl hydrocarbon receptor and peroxisome proliferator-activated receptor $\alpha$ at the crossroads of toxicokinetics and toxicodynamics. Basic Clin Pharmacol Toxicol 123: 42-50, 2018. PMID: 2952 7807. DOI: $10.1111 /$ bcpt.13004

14 De Mattia E, Cecchin E, Roncato R and Toffoli G: Pregnane X receptor, constitutive androstane receptor and hepatocyte nuclear factors as emerging players in cancer precision medicine. Pharmacogenomics 17(14): 1547-1571. 2016. PMID: 27561454. DOI: $10.2217 /$ pgs-2016-0095

15 Wang D, Li L, Yang H, Ferguson SS, Baer MR, Gartenhaus RB and Wang $\mathrm{H}$ : The constitutive androstane receptor is a novel therapeutic target facilitating cyclophosphamide-based treatment of hematopoietic malignancies. Blood 121(2): 329-338, 2013. PMID: 23160467. DOI: 10.1182/blood-2012-06-436691

16 Peters JM, Shah YM and Gonzalez FJ: The role of peroxisome proliferator-activated receptors in carcinogenesis and chemoprevention. Nat Rev Cancer 12(3): 181-195, 2012. PMID: 22318237. DOI: $10.1038 / \mathrm{nrc} 3214$

17 Pondugula SR and Mani S: Pregnane xenobiotic receptor in cancer pathogenesis and therapeutic response. Cancer Lett 328(1): 1-9, 2013. PMID: 22939994. DOI: 10.1016/j.canlet. 2012.08.030

18 Estrela GR, Wasinski F, Batista RO, Hiyane MI, Felizardo RJ, Cunha F, de Almeida DC, Malheiros DM, Câmara NO, Barros $\mathrm{CC}$, Bader $\mathrm{M}$ and Araujo RC: Caloric restriction is more efficient than physical exercise to protect from cisplatin nephrotoxicity via PPAR-alpha activation. Front Physiol 8: 116, 2017. PMID: 28303105. DOI: 10.3389/fphys.2017.00116

19 Kim SJ, Park C, Lee JN and Park R: Protective roles of fenofibrate against cisplatin-induced ototoxicity by the rescue of peroxisomal and mitochondrial dysfunction. Toxicol Appl Pharmacol 353: 43-54, 2018. PMID: 29908243. DOI: 10.1016/ j.taap.2018.06.010

20 De Lellis L, Cimini A, Veschi S, Benedetti E, Amoroso R, Cama A and Ammazzalorso A: The Anticancer potential of peroxisome proliferator-activated receptor antagonists. ChemMedChem 13(3): 209-219, 2018. PMID: 29276815. DOI: 10.1002/ cmdc. 201700703
21 Albermann N, Schmitz-Winnenthal FH, Z'graggen K, Volk C, Hoffmann MM, Haefeli WE and Weiss J: Expression of the drug transporters MDR1/ABCB1, MRP1/ABCC1, MRP2/ABCC2, BCRP/ABCG2, and PXR in peripheral blood mononuclear cells and their relationship with the expression in intestine and liver. Biochem Pharmacol 70(6): 949-958, 2005. PMID: 16054595. DOI: $10.1016 /$ j.bcp.2005.06.018

22 Burk O, Arnold KA, Geick A, Tegude H and Eichelbaum M: A role for constitutive androstane receptor in the regulation of human intestinal MDR1 expression. Biol Chem 386(6): 503-513, 2005. PMID: 16006237. DOI: 10.1515/BC.2005.060

23 Gupta D, Venkatesh M, Wang H, Kim S, Sinz M, Goldberg GL, Whitney K, Longley $\mathrm{C}$ and Mani S: Expanding the roles for pregnane $\mathrm{X}$ receptor in cancer: proliferation and drug resistance in ovarian cancer. Clin Cancer Res 14(17): 5332-5340, 2008. PMID: 18765524. DOI: 10.1158/1078-0432.CCR-08-1033

24 Harmsen S, Meijerman I, Febus CL, Maas-Bakker RF, Beijnen JH and Schellens JH: PXR-mediated induction of P-glycoprotein by anticancer drugs in a human colon adenocarcinoma-derived cell line. Cancer Chemother Pharmacol 66(4): 765-771, 2010. PMID: 20041327. DOI: 10.1007/s00280-009-1221-4

25 Mani S, Huang H, Sundarababu S, Liu W, Kalpana G, Smith AB and Horwitz SB: Activation of the steroid and xenobiotic receptor (human pregnane $\mathrm{X}$ receptor) by nontaxane microtubule-stabilizing agents. Clin Cancer Res 11(17): 63596369, 2005. PMID: 16144941. DOI: 10.1158/1078-0432.CCR05-0252

26 Wang H, Huang H, Li H, Teotico DG, Sinz M, Baker SD, Staudinger J, Kalpana G, Redinbo MR and Mani S: Activated pregnenolone $\mathrm{X}$-receptor is a target for ketoconazole and its analogs. Clin Cancer Res 13(8): 2488-2495, 2007. PMID: 17438109. DOI: $10.1158 / 1078-0432$.CCR-06-1592

27 Mani S, Dou W and Redinbo MR: PXR antagonists and implication in drug metabolism. Drug Metab Rev 45(1): 60-72, 2013. PMID: 23330542. DOI: $10.3109 / 03602532.2012 .746363$

28 Staudinger JL: Clinical applications of small molecule inhibitors of pregnane X receptor. Mol Cell Endocrinol 485: 61-71, 2019. PMID: 30726709. DOI: 10.1016/j.mce.2019.02.002

29 Ekins S, Kholodovych V, Ai N, Sinz M, Gal J, Gera L, Welsh WJ, Bachmann K and Mani S: Computational discovery of novel low micromolar human pregnane $\mathrm{X}$ receptor antagonists. Mol Pharmacol 74(3): 662-672, 2008. PMID: 18579710. DOI: $10.1124 / \mathrm{mol} .108 .049437$ 